Table 1. Illustrative Provider and Patient Quotations from Source Studies

\begin{tabular}{|c|c|c|}
\hline Analytical Theme & Quotation & Reference \\
\hline \multicolumn{3}{|l|}{ Provider Barriers } \\
\hline $\begin{array}{l}\text { Knowledge gaps and } \\
\text { management } \\
\text { approaches }\end{array}$ & $\begin{array}{l}\text { "I think that there is lack of knowledge by both patients and } \\
\text { health professionals. I just thought you just had gout flare ups } \\
\text { and then it just went away, so there is definitely a need for } \\
\text { education and better training." }\end{array}$ & $\begin{array}{l}\text { Spencer et } \\
\text { al. }\end{array}$ \\
\hline $\begin{array}{l}\text { Perceptions and } \\
\text { beliefs about gout } \\
\text { patients }\end{array}$ & $\begin{array}{l}\text { "Adherence to uric acid-lowering therapy is not a problem in } \\
\text { patients with gout, since they are well aware of the fact they will } \\
\text { get new gout attacks if they do not take their medication." }\end{array}$ & $\begin{array}{l}\text { Spaetgens } \\
\text { et al. }\end{array}$ \\
\hline $\begin{array}{l}\text { System barriers to } \\
\text { optimal gout care }\end{array}$ & $\begin{array}{l}\text { "It's another thing, too, the time issue. Cause if you're really, } \\
\text { really busy, you don't spend time to talk to the patient, you don't } \\
\text { have time, if we're busy." }\end{array}$ & $\begin{array}{l}\text { Humphrey } \\
\text { et al. }\end{array}$ \\
\hline \multicolumn{3}{|l|}{ Patient Barriers } \\
\hline $\begin{array}{l}\text { Limited gout } \\
\text { knowledge }\end{array}$ & $\begin{array}{l}\text { "I think I have accepted the fact that there is no cure. It is up to } \\
\text { me just to minimize it, I think. I don't think there is any cure } \\
\text { because I haven't talked to anybody who has had it and say } \\
\text { they don't get it anymore. Is that possible?" }\end{array}$ & $\begin{array}{l}\text { Lindsay et } \\
\text { al. }\end{array}$ \\
\hline $\begin{array}{l}\text { Attitudes toward taking } \\
\text { medication }\end{array}$ & $\begin{array}{l}\text { "So I know gout's never going to kill me, right. So I don't want to } \\
\text { be taking - I don't want to be rattling around full of tablets all the } \\
\text { time". }\end{array}$ & $\begin{array}{l}\text { Richardson } \\
\text { et al. }\end{array}$ \\
\hline $\begin{array}{l}\text { Interactions with } \\
\text { healthcare providers }\end{array}$ & $\begin{array}{l}\text { "I don't think they gave you enough. It kind of wasn't even the } \\
\text { basics. There were no follow-ups or anything and I was going } \\
\text { regularly. There must have been time in there. I didn't know } \\
\text { about uric acid levels or what I should aim for. In my mind, I } \\
\text { never had it explained." }\end{array}$ & $\begin{array}{l}\text { Te Karu et } \\
\text { al. }\end{array}$ \\
\hline $\begin{array}{l}\text { Practical barriers to } \\
\text { chronic medication use }\end{array}$ & $\begin{array}{l}\text { "I'm frequently too busy with school pressures to worry about } \\
\text { taking medication regularly." }\end{array}$ & Katz et al. \\
\hline
\end{tabular}

Conclusions: Our thematic synthesis identified several barriers to gout care, particularly knowledge gaps among both providers and patients as well as implementation barriers to the provision of optimal care. Knowledge translation initiatives emphasizing the "curable" nature of gout targeting both providers and patients as well as strategies to reduce system barriers and support regular medication use are urgently needed to improve gout care.

Acknowledgements: This study was supported in part by a grant from the Canadian Institutes of Health Research (PCS 146388). We wish to thank the Arthritis Patient Advisory Board of Arthritis Research Canada for providing their consumer input into this project.

Disclosure of Interest: None declared

DOI: 10.1136/annrheumdis-2017-eular.4298

\section{THU0461 ACCURACY OF HUMASENS-PLUS POINT-OF-CARE URIC ACID METER USING CAPILLARY BLOOD OBTAINED BY FINGERTIP PUNCTURE}

S. Fabre $^{1}$, P. Clerson ${ }^{2}$, J.-M. Launay ${ }^{3}$, J.-F. Gautier ${ }^{4}$, T. Vidal-Trecan ${ }^{4}$, J.-P. Riveline ${ }^{4}$, A. Platt ${ }^{5}$, A. Abrahamsson 6 , J.N. Miner ${ }^{7}$, G. Hughes ${ }^{5}$,' P. Richette ${ }^{1}$, T. Bardin ${ }^{1} .{ }^{1}$ Rheumatology department, Hôpital Lariboisière, Paris; ${ }^{2}$ Soladis Clinical Studies, Roubaix; ${ }^{3}$ Biochemistry department; ${ }^{4}$ Diabetology department, Hôpital Lariboisière, Paris, France; ${ }^{5}$ Personalised Healthcare Unit, AstraZeneca, Cambridge, United Kingdom; ${ }^{6}$ Personalised Healthcare Unit, AstraZeneca, Mölndal, Sweden; ${ }^{7}$ Research and development, Ardea Biosciences Inc., San Diego, CA, United States

Background: A key factor in the success of gout management is the long-term lowering of uricemia below predetermined targets (300 or $360 \mu \mathrm{mol} / \mathrm{l})$. Monitoring of uricemia in gout patients is therefore important, and is presently done in the laboratory on plasma samples obtained after venous puncture. An accurate uric acid (UA) meter allowing rapid testing by the health care professionals and self-measurement by the patient should improve management of gout.

Objectives: This study aimed to assess the reliability of immediate UA measurement in capillary blood samples obtained from fingertip puncture using the HumaSens $^{\text {Plus }}$ point-of-care meter (meter) compared with that of a standard laboratory assay (lab).

Methods: Capillary UA levels were measured from 236 consenting diabetic patients using the commercially available HumaSens $s^{\text {Plus }}$ UA meter (European Conformity marked and approved for EU market use). Each patient also had a plasma UA measurement in the biochemistry laboratory using an uricase automated colorimetric assay. Since the UA meter has a dynamic range of 180 $1190 \mu \mathrm{mol} / \mathrm{l}$, when the values were out-ranged (meter reading LO or $\mathrm{HI}$ ), they were individually compared to corresponding plasma measurements. Agreement between capillary and plasma UA levels was assessed by Intraclass Correlation Coefficient (ICC) and Bland-Altman graphic representation. Best capillary UA threshold for detection of hyperuricemia (plasma UA $>360 \mu \mathrm{mol} / \mathrm{l}$ ) was determined from a ROC curve, relationship between methods were identified by regression. Impact of potential confounding factors (biological parameters/treatments) was searched. A total of 206 paired measurements were required for estimation of an ICC of 0.80 with a precision of 0.10 at alpha risk of $0.05 \%$. To better understand discrepancies between meter and lab, results were compared to reference plasma UA measurements by liquid chromatography-mass spectrometry (LC-MS) in a subgroup of 77 patients who gave complementary consent.

Results: Fourteen capillary samples were read LO by the meter: 11 were confirmed by lab to be below $180 \mu \mathrm{mol} / \mathrm{l}$ and 3 were above $(189,206$ and $428 \mu \mathrm{mol} / \mathrm{l})$. Two capillary samples were read $\mathrm{HI}$ and were measured at 303 and $213 \mu \mathrm{mol} / \mathrm{l}$ by lab. In the remaining 222 samples with meter and lab values, ICC was 0.90 [0.87-0.92] and Bland-Altman curve showed acceptable agreement over all the tested values. Best meter threshold for detection of hyperuricemia by the HumaSens ${ }^{\text {Plus }}$ meter was $330 \mu \mathrm{mol} / /$ (sensitivity 0.89 , specificity 0.89 , area under the ROC curve 0.95). Based on regression, plasma uricase of
$360 \mu \mathrm{mol} / \mathrm{l}$ corresponded to $343 \mu \mathrm{mol} / \mathrm{l}$. Among the biological parameters tested, only hematocrit impacted capillary uric acid measurements, however negligibly. No medication appeared to significantly affect test results. Plasma uricase measurements were better correlated to LC-MS measurements ( $r=0.98[0.96-$ $0.99])$ than capillary measurements $(r=0.84[0.75-0.90])$.

Conclusions: Results of the HumaSens ${ }^{\text {Plus }}$ meter were reasonably comparable to those of the laboratory assay. It is easy to use and may be useful in clinic and in epidemiologic studies.

Disclosure of Interest: None declared

DOI: 10.1136/annrheumdis-2017-eular.2787

\section{THU0462 MORTALITY IN PATIENTS WITH GOUT: A SYSTEMATIC REVIEW}

S. Mitchell ${ }^{1}$, H. Liedgens ${ }^{2}$, E. Johannes ${ }^{3} \cdot{ }^{1}$ Decision Resources Group, Bicester, United Kingdom; ${ }^{2}$ Head Health Economics and Outcomes Research Market Access, SBU Europe; ${ }^{3} \mathrm{Head}$ Market Access Europe, Grünenthal GmbH, Aachen, Germany

Background: Gout is a chronic, progressive, inflammatory disease characterised by elevated serum uric acid (sUA) levels (1). In Europe the prevalence of gout ranges from $0.9-2.5 \%$, and is increasing (2). Published data indicate that gout is an independent risk factor for both all-cause and cardiovascular (CV)-related mortality $(3,4)$.

Objectives: To conduct a systematic review to identify studies reporting the association between gout and mortality (all-cause and CV-related).

Methods: Relevant publications were identified by interrogating electronic databases; Medline \& MEDLINE In-Process, EMBASE and the Cochrane Library (accessed 3 May 2016). Eligibility criteria included adult patients with a definitive diagnosis of acute/chronic gout (self-reported/physician diagnosed), with no restriction on publication date, study design or geography.

Results: Nineteen studies met the pre-defined inclusion criteria and were reviewed. The studies were conducted in: the US $(n=8)$; Taiwan $(n=5)$; Canada $(n=3)$; Spain $(n=1)$; Singapore $(n=1)$; and the UK $(n=1)$. In addition to patients having a diagnosis of acute/chronic gout, 6 of the 19 studies were conducted in the following patient subgroups: renal transplant $(n=1)$; chronic kidney disease $(n=2)$; patients with a recent acute myocardial infraction $(n=2)$; and patients with heart failure $(n=1)$. There were several consistent finding across the 19 studies: (i) gout was associated with an increase in both all-cause mortality (reported hazard ratios [HR] ranged from 1.13 to 2.37 ) and CV-related mortality (reported HR ranged from 1.10 to 3.88 ) compared with patients without gout; (ii) the increased risk in all-cause mortality was primarily driven by an increase in CV-related mortality; (iii) the increased mortality risk was higher in females than males. One study reported that the presence of tophi was independently associated with a higher risk of all-cause mortality. Notably one study reported that patients who received urate-lowering therapy (ULT) have a statistically significant lower all-cause mortality and CV-related mortality risk relative to patients who do not receive ULT.

Conclusions: This systematic review confirms that gout is associated with an increased risk of all-cause and CV-related mortality; this was consistently reported across the eligible studies. The findings highlight the risk associated with gout and emphasise the need for appropriate treatment of this curable disease.

\section{References:}

[1] Keenan R, et al. Etiology and pathogenesis of hyperuricemia and gout. Kelley's textbook of rheumatology. Elsevier Saunders. 2013:94:1533-53.

[2] Richette P, et al. 2016 updated EULAR evidence-based recommendations for the management of gout. Ann Rheum Dis. 2016:annrheumdis-2016-209707.

[3] Lottmann K, et al. Association between gout and all-cause as well as cardiovascular mortality: a systematic review. Curr Rheumatol Rep. 2012;14(2):195-203. [4] Clarson L, et al. Increased cardiovascular mortality associated with gout: a systematic review and meta-analysis. Eur J Prev Cardiol. 2015;22(2):335-43. Disclosure of Interest: S. Mitchell: None declared, H. Liedgens Employee of: Grünenthal GmbH, E. Johannes Employee of: Grünenthal GmbH DOI: 10.1136/annrheumdis-2017-eular.6062

\section{THU0463 EPIDEMIOLOGY OF GOUT AND HYPERURICEMIA IN NEW CALEDONIA}

$\mathrm{T}_{\text {T. Bardin }}{ }^{1}$, E. Magnat ${ }^{2}$, P. Clerson ${ }^{3}$, P. Richette ${ }^{4}$, B. Rouchon ${ }^{2} .{ }^{1}$ Rheumatology, Hôpital lariboisière, Paris, France; ${ }^{2}$ Agence Sanitaire et Sociale, Nouméa, New Caledonia; ${ }^{3}$ Soladis Clinical Studies, Roubaix; ${ }^{4}$ Rheumatolofy, Hôpital Lariboisière, Paris, France

Background: New Caledonia is a Pacific island of 270.000 inhabitants with mixed ethnicities, including Melanesians (39.1\%) and Polynesians (10.2\%) and people from European ancestry (27.2\%).

Objectives: To determine the prevalence of gout and hyperuricemia in the various ethnicities and to characterize associated factors.

Methods: A 3-degree random sample of the population aged 18 to 60 years old was redressed according to the 2014 New Caledonia census. Face-to-face interviews were performed by trained nurses who used a predefined questionnaire along with planned physical measurements. All participants underwent capillary measurement of creatinine level (StatSensor) and all men and only women older 
than 40 years underwent uricemia testing (HumaSens). Gout was defined by a validated algorithm (1). Hyperuricemia was defined by capillary level equivalent to plasma uric acid level (PUA) $>6 \mathrm{mg} / \mathrm{dl}$ (2) and/or urate lowering drug (ULD) prescription.

Results: 1.144 participants (mean age 37.7 years; $50.4 \%$ men) were included. Prevalence of gout in the entire redressed sample was $3.3 \%(95 \% \mathrm{Cl} 2.2-4.9)$. The prevalence was $4.1 \%(1.8-8.9), 2.6 \%(1.4-4.7), 6.7 \%(2.5-16.8)$, and $1.9 \%(0.5-6.6)$ for Europeans, Melanesians, Polynesians and other ethnicities, respectively. After adjustment for age and sex, Polynesians showed higher risk for gout than Europeans (adjusted odds ratio [aOR] 4.57 [95\% Cl 1.3-16.7]). Prevalence of hyperuricemia, determined in 658 participants, was $67.0 \%(95 \% \mathrm{Cl}$ 61.9-71.6). Prevalence of hyperuricemia was greater for Polynesians (aOR 9.17 [3.2-26.4]), Melanesians (aOR 4.02 [2.2-7.2]) and other ethnicities (aOR 2.18 [1.1-4.5]) than Europeans. On univariate analysis, factors associated with gout were hyperuricemia, male gender, age, BMI, waist circumference, renal failure, hypertension, diabetes, history of major episodes of depression and cancer but not dietary factors or physical activity, despite a consistent association with BMI. Among gout and non-gout patients, $45.9 \%$ and $0.7 \%$ were receiving ULT. Overall, $29.6 \%$ of patients receiving ULD had proper control of PUA levels $(\leq 6 \mathrm{mg} / \mathrm{dl})$. Conclusions: As compared with Europe, in New Caledonia, the prevalence of gout and hyperuricemia was high, including in patients with European descent, as was previously reported for New Zealand (3). The prevalence of gout and hyperuricemia differed by ethnicity. For Melanesians, the prevalence of hyperuricemia was higher but risk of gout similar to that for Europeans, so factors (e.g., genetics) other than those involved in hyperuricemia may intervene in the risk of gout.

References:

[1] Richette et al. Ann Rheum Dis 2015;74:1684-90.

[2] Fabre et al ACR meeting, Washington 2016.

[3] Winnard et al Rheumatology 2012;51:901-9.

Disclosure of Interest: None declared

DOI: 10.1136/annrheumdis-2017-eular.3409

\section{THU0464 A GENOME-WIDE ASSOCIATION STUDY OF GOUT IN PEOPLE OF EUROPEAN ANCESTRY}

T.R. Merriman ${ }^{1}$, M. Cadzow ${ }^{1}$, M. Merriman ${ }^{1}$, A. Phipps-Green ${ }^{1}$, R. Topless ${ }^{1}$, A. Abhishek ${ }^{2}$, M. Andres ${ }^{3}$, L. Bradbury ${ }^{4}$, R. Buchanan ${ }^{5}$, K. Cremin ${ }^{6}$, E. de Guzman $^{4}$, J. de Zoysa ${ }^{7}$, M. Doherty ${ }^{2}$, C. Hill ${ }^{8}$, T. Huizinga ${ }^{9}$, T. Jansen ${ }^{10}$, M. Janssen ${ }^{11}$, L. Joosten ${ }^{12}$, F. Kurreeman ${ }^{9}$, S. Lester ${ }^{8}$, F. Liote ${ }^{13}$, D. Macartney-Coxson ${ }^{14}$, H. Matsuo ${ }^{15}$, G. McCarthy ${ }^{16}$, S. McCormick $^{1}$, R. Murphy ${ }^{7}$, K. Pavelka ${ }^{17}$, F. Perez-Ruiz ${ }^{18}$, J. Puig ${ }^{19}$, T. Radstake 20 , P. Riches ${ }^{21}$, M. Rischmueller ${ }^{8}$, E. Roddy ${ }^{22}$, M. Smith ${ }^{23}$, E. Stahl ${ }^{24}$ B. Stiburkova ${ }^{17}$, R. Stubbs ${ }^{25}$, A.-K. Tausche ${ }^{26}$, R. Torres ${ }^{19}$, R. Walker ${ }^{1}$, K. Yamamoto ${ }^{27}$, M. Brown ${ }^{4}$, H. Choi ${ }^{28}$, N. Dalbeth ${ }^{7}$, A. So ${ }^{29}$, L. Stamp ${ }^{1}$, T. Flynn ${ }^{1} .{ }^{1}$ University of Otago, Dunedin, New Zealand; ${ }^{2}$ University of Nottingham, Nottingham, United Kingdom; ${ }^{3}$ Universidad Miguel Hernández, Alicante, Spain; ${ }^{4}$ Queensland University of Technology, Brisbane; ${ }^{5}$ University of Melbourne, Melbourne; ${ }^{6}$ University of Queensland, Brisbane, Australia; ${ }^{7}$ University of Auckland, Auckland, New Zealand; ${ }^{8}$ Queen Elizabeth Hospital, Adelaide, Australia; ${ }^{9}$ Leiden University Medical Center, Leiden; ${ }^{10}$ VieCuri Medical Centre, Venlo; ${ }^{11}$ Rijnstate Hospital, Arnhem; ${ }^{12}$ Radboud University Medical Center, Nijmegen, Netherlands: ${ }^{13}$ Hospital Lariboisière, Paris. France; ${ }^{14}$ Environmental and Scientific Research, Wellington, New Zealand; ${ }^{15}$ National Defense Medical College, Saitama, Japan; ${ }^{16}$ University College Dublin, Dublin, Ireland; ${ }^{17}$ institute of Rheumatology, Prague, Czech Republic; ${ }^{18} \mathrm{Hospital}$ de Cruces, Vizcaya; ${ }^{19}$ Hospital Universitario la Paz, Madrid, Spain; ${ }^{20}$ University Medical Centre Utrecht, Utrecht, Netherlands; ${ }^{21}$ University of Edinburgh, Edinburgh; ${ }^{22}$ Keele University, Newcastle, United Kingdom; ${ }^{23}$ Flinders Medical Centre and Repatriation Hospita, Adelaide, Australia; ${ }^{24} \mathrm{Mt}$ Sinai School of Medicine, New York, United States; ${ }^{25} \mathrm{P} 3$ Research Ltd, Wellington, New Zealand; ${ }^{26}$ University of Dresden, Dresden, Germany; ${ }^{27}$ Kurume University, Kurume, Japan; ${ }^{28}$ Harvard Medical School, Boston, United States; ${ }^{29}$ University of Lausanne, Lausanne, Switzerland

Background: Gout progresses through three stages: hyperuricemia, deposition of monosodium urate (MSU) crystals, and innate immune system response to MSU crystals. Genome wide association studies (GWAS) have provided insight into the molecular control of progression to hyperuricemia. However, less is known about the progression from hyperuricemia to gout.

Objectives: To conduct a GWAS for gout (where an immune response to MSU crystals has occurred) using 5,835 cases - the largest GWAS of gout to date.

Methods: The GWAS comprised 3 data sets: NZ/Eurogout (2,365 clinicallyascertained cases; 1,485 controls), the Health Professionals Follow-Up (HPFS) and Nurses' Health Studies (NHS) (1,038 cases, self-ascertained using ACR criteria; 1,095 controls), and UK Biobank (2,432 cases, ascertained by self-report of gout, hospital records, and/or use of urate-lowering therapy; 102,989 controls). The NZ/Eurogout samples were genotyped using the Illumina CoreExome v24 bead chip array (547,644 markers), the HPFS/NHS samples using the Illumina OmniExpress v12 bead chip array (730,525 markers), and the UK Biobank samples using an Affymetrix Axiom array (820,967 markers). UK Biobank genotypes had been imputed to $733.3 \mathrm{M}$ SNPs. Neither the NZ/Eurogout nor NHS/HPFS genotype sets were imputed. Markers common to all three data sets
$(279,939)$ were associated with gout (adjusted for sex, age) within each data set separately using PLINK 1.9. An inverse-variance weighted meta-analysis was done with meta v4.4 in R.

Results: There were seven loci with genome-wide significant $\left(P<5 \times 10^{-8}\right)$ evidence for association with gout: SLC2A9 (OR=1.67), ABCG2(OR=1.72), GCKR (OR=1.24), SLC17A1-A4 (OR=1.20), SLC22A12 (OR=1.21), PDZK1 (OR=1.14), TRIM46 (OR=1.18).

Conclusions: All seven loci have been previously associated with serum urate levels in GWAS. Our data emphasise the relative importance of genetic control of serum urate, compared to the genetic control of MSU crystal formation or the innate immune response, in determining gout.

Disclosure of Interest: None declared

DOI: 10.1136/annrheumdis-2017-eular.5634

\section{THU0465 CALCIUM PYROPHOSPHATE DEPOSITION DISEASE AND OSTEOARTHRITIS: TWO FACES OF THE SAME MEDAL? AN ULTRASONOGRAPHIC AND MICROSCOPY STUDY}

V. Picerno ${ }^{1}$, A. Scanu ${ }^{2}$, A. Adinolfi ${ }^{1}$, C.A. Scirè ${ }^{3}$, B. Frediani ${ }^{1}$, L. Punzi ${ }^{2}$, G. Filippou ${ }^{1} .{ }^{1}$ University of Siena, Siena; ${ }^{2}$ University of Padua, Padua; ${ }^{3}$ University of Ferrara, Ferrara, Italy

Background: Calcium pyrophosphate deposition disease (CPPD) and Osteoarthritis $(\mathrm{OA})$ are frequently associated and CPPD with OA is recognized as a clinical subtype [1]. However, the differences in pathogenetic, microscopic and clinical aspects between the two diseases are not clear and how CPPD and OA could affect each other is still a matter of debate.

Objectives: To assess the differences between CPPD and OA in terms of anatomic alterations of the joint, evaluated with US, and characteristics of the synovial fluid (SF) of knees affected by CPPD and/or OA.

Methods: consecutive patients reaching the outpatient clinic for the presence of knee pain and with any amount of joint effusion were eligible for the study. Patients with diagnosis or suspicion of chronic inflammatory rheumatic conditions were excluded. All enrolled patients underwent US of the knee for the assessment of joint effusion (JE), synovial hypertrophy (SH), synovial power Doppler (PD), femuro-tibial osteophytes (FTO) and alterations of the femoral hyaline cartilage (FHC), using a semiquantitative score (0: normal to 3 : severe alteration) and finally a US guided aspiration of the SF. SF was examined by optical and polarized light microscopy to determine total and differential white blood cell (WBC) counts, and for crystal identification. The concentration of the main inorganic ions involved in CPP crystal formation $\left(\mathrm{P}_{2} \mathrm{O}_{-}^{4-}, \mathrm{PO}_{4}^{3-}, \mathrm{Ca}^{2+}\right.$ and $\left.\mathrm{Mg}^{2+}\right)$ was assessed by fluorometric and colorimetric assays. CPP crystal detection was also used for the classification of patients. Further, in CPPD patients, a count of the CPP crystals detectable in a single slide was carried out. Depending on the variables, chi-square, Mann Whitney and Spearman Ro tests were used for statistical analysis.

Results: 49 patients ( 28 women), mean age 70.29 yo $(S D \pm 10.93)$ were enrolled in the study; 23 subjects presented OA and 26 CPPD (23.07\% acute arthritis, $77.6 \%$ CPPD with OA). At US, a statistically significant difference between CPPD and OA was found only for the grade of effusion, being more abundant in CPPD patients. On the contrary, no differences were found regarding SH, PD, FTO, FHC. SF analysis showed that CPPD patients presented a higher volume of SF, a higher total WBC count with a higher polymorphonuclear (PMN) cells percentage and lower monocytes percentage than patients with OA. Further, both total cell count and PMN percentage were positively correlated with the number of crystals in the SF. On the other hand, no statistically significant differences were found in the content of inorganic ions between the two groups.

Conclusions: According to these results, patients with CPPD and OA present some distinct features, mainly regarding the characteristics of the SF, compared to patients with $\mathrm{OA}$ alone. These differences may reflect different underlying pathogenetic pathways for the two diseases. Surprisingly, the concentration of inorganic ions in the two populations was similar.Further studies are necessary in order to better understand the link between CPPD and OA and the role of ions concentration in the SF for the formation of crystals.

References:

[1] Zhang W et al. European League Against Rheumatism reccomandations for calcium pyrophosphate deposition. Pat I: terminology and diagnosis. Ann Rheum Dis 2011; 70: 563-570.

Disclosure of Interest: None declared

DOI: 10.1136/annrheumdis-2017-eular.6606

\section{THU0467 SAFETY AND EFFICACY OF FEBUXOSTAT IN ADVANCED CKD PATIENTS WITH HYPERURICEMIA}

Y.-J. Oh, E.S. Park, S.S. Ahn, K.Y. Lee, S.-J. Byun, J.Y. Pyo, S.M. Jung, S.-W. Lee, Y.-B. Park, J.J. Song. Internal medicine, Yonsei University College of Medicine, Seoul, Korea, Republic Of

Background: In chronic kidney disease (CKD) patients, hyperuricemia is a common finding and might be one of modifiable risk factors for renal progression. However, dosing adjustments and increased risk of serious side effects of uric acid lowering agents in patients with reduced renal function lead to undercorrection of hyperuricemia, especially in patients with advanced CKD. Febuxostat is highly 